\title{
Posicionamiento del derecho de acceso a la información pública en Chile
}

\author{
Positioning of the right of access to public information in Chile
}

Christian Anker

\section{Introducción}

En abril del 2009 entró en vigencia la Ley 20.285, que aprueba la Ley de Transparencia de la función pública y de acceso a la información de la Administración del Estado. Esta ley establece que cualquier persona puede acceder a información pública, que se encuentre en poder de órganos y servicios de la Administración del Estado, estableciendo los procedimientos para solicitarla. También crea el Consejo para la Transparencia (CPLT), un órgano autónomo que vela por el cumplimiento de la normativa.

La Ley pretende instalarse "no sólo como el mecanismo por el cual se permite el acceso a la información pública, sino que además es el elemento normativo que, al reconocer un nuevo derecho ciudadano, potencia la participación y empoderamiento de la ciudadanía, al mismo tiempo que mejora la gestión institucional" (Biblioteca del Congreso Nacional, 2013). En este sentido, a medida que los ciudadanos conozcan de mejor manera la Ley y la función del Consejo, es esperable que los ciudadanos requieran más información de los órganos públicos y una acción de control ciudadano más activo.

La solicitud de información es el ejercicio de una acción guiada por un propósito, es decir por el interés o deseo de obtener una información que no está publicada y que satisfaga la necesidad de conocer un dato, hecho o situación, propio de una institución. La información es un medio para lograr un fin esperado, es una herramienta para el ejercicio de otros derechos o para exigir una gestión pública más eficiente. Los objetivos de funcionamiento del CPLT se centran en promover el principio de transparencia y difundir el derecho de acceso a la información pública, velando por la accesibilidad, exigibilidad y disponibilidad de la información; fiscalizando el cumplimiento de la normativa; perfeccionando su regulación; favoreciendo la eficiencia de la gestión pública y el control ciudadano; y especialmente instalando y posicionando el CPLT en base a un modelo que promueve la participación ciudadana, incorporando experiencias comparadas y mejores prácticas institucionales.

*Dirección de correspondencia [Correspondence address]: Christian Anker,

E-mail: cankeru@yahoo.es
En este artículo se evalúa el escenario actual de implementación en materia del derecho de acceso a la información pública y el rol del Consejo para la Transparencia en Chile, a través de la definición segmentos de clientes y aéreas estratégicas para focalizar la estrategia de posicionamiento.

De esta manera, el objetivo de este artículo es describir la estrategia de posicionamiento que ha tenido el Derecho de Acceso a la Información (DAI) en Chile.

\section{Análisis y propuesta de seg- mentación}

Según los principios del marketing, una de las principales vías para abordar la temática del posicionamiento es realizar una segmentación de los diversos clientes y también de los "mercados" frente a los cuales la Organización tiene una participación real o potencial (Kotler y Amstrong, 2008). En este sentido, se hace relevante realizar una segmentación o clasificación tanto de los órganos obligados por Ley de Transparencia, relevando sus características para que el CPLT pueda ejercer adecuadamente su mandato de manera más estratégica, como también visualizar una segmentación para conocer los clientes, tanto de aquellos que son parte de estos organismo, -que llamaremos "clientes públicos"-, como aquellos clientes que son parte de la esfera del mundo social y privado, -que llamaremos "clientes privados".

\section{Propuestas de acciones de segmenta- ción para el posicionamiento}

Según los resultados de los estudios que ha realizado el CPLT durante su funcionamiento, existen diversos riesgos y variables influyentes en su ámbito del posicionamiento institucional. Dentro de ello encontramos el riesgo de que este derecho sea percibido por los ciudadanos como algo etéreo e inasible, alejado de las necesidades sociales concretas que existen en las realidades subjetivas. Es difícil que la temática del derecho de acceso a la información pública pueda competir con ámbitos como salud, educación o vivienda. Por tanto, la variable de ries- 
go en el posicionamiento se basa en lo complejo de hacer evidente y concreto este nuevo derecho, y de cómo ayudan indirectamente al mejoramiento de la gestión pública y al desarrollo de un Estado democrático. Ello acarrea costos de transacción en las eventuales acciones de posicionamiento de los beneficios, los cuales pueden verse perjudicados por la desconfianza ciudadana que hay en el quehacer de las instituciones públicas.

Por tal motivo, un elemento esencial en la estrategia de posicionamiento debe centrarse en una estrategia mediata basada en la difusión y habilitación del derecho (educación-capacitación), más que en las acciones inmediatas de posicionamiento a través de medios de comunicación masivas. Se requiere empoderar tanto a los clientes públicos como a los privados en el ejercicio de este derecho, ya que dicho ejercicio sólo aparece tras un encuentro entre la identificación social del control ciudadano y una gestión pública exitosa.

También se observa que desde la gestión de los organismos públicos se ha reaccionado con una tramitación de una SAI como otra carga burocrática más, dentro del abanico de acciones públicas cotidianas, generándose una merma en la oportunidad en la satisfacción de la demanda "inmediata" de respuesta del ciudadano.

La responsabilidad interna del funcionario público que gestiona la SAI debe luchar con la cultura de opacidad propia del órgano y en algunas veces con la voluntad del jefe de servicio de hacer pública dicha información, lo cual trae aparejados muchos riesgos internos, tanto políticos, institucionales, y de prestigio institucional.

\section{El posicionamiento en los "clientes privados" o sujetos de derecho.}

Como clientes privados, reconocemos a los ciudadanos que participan, o no,de algún tipo de organización social . Frente a este grupo, el CPLT debe hacerse cargo del riesgo de la "intangibilidad", por lo que debe ajustar su mensaje a las temáticas de interés de la sociedad organizada. Destacan los dirigentes comunales quienes buscan un incentivo concreto para mejorar la participación social de los miembros de las organizaciones dirigidas. También destacan los periodistas y académicos quienes asumen el ejercicio del acceso a la información como parte de una formación cívica de los ciudadanos, enfatizando el valor público que genera la transparencia.

Por otro lado, podemos identificar a los ciudadanos que trabajan en el Estado. Ellos han demostra- do ser usuarios frecuentes de esta ley y por tanto del CPLT, pero también, porque son un tipo de segmento en el que CPLT tiene una rápida llegada, al ser un mercado potencialmente activo.

La Sociedad Civil es un actor fundamental en el posicionamiento, ya que se constituye como un canal efectivo y dinámico para hacer llegar los principales contenidos y materias del ejercicio de solicitar información, generando un efecto de amplificación.

\section{El posicionamiento en los "clientes públicos" o sujetos obligados.}

El grupo de instituciones que están bajo la fiscalización del CPLT son los organismos de Gobierno, las 345 Municipalidades, las 54 Corporaciones Municipales, las 16 Universidades Públicas y las 6 Fundaciones de la Primera Dama. En el caso de las Empresas Públicas existen obligaciones de transparencia activa.

Este cliente manifiesta una actitud "ambivalente" hacia la LT, ya que si bien la valora, en tanto ésta genera una modernización del sector público y de sus procesos, se siente sobrepasado por las obligaciones que se le imponen, unidos a la falta de recursos físicos y humanos necesarios para cumplir a cabalidad con lo demandado. A su vez este cliente puede verse afectado por percepciones injustificadas de los clientes privados hacia el sector público en general, los cual puede afectar la forma en la que enfrenta al ciudadano y sus solicitudes de información.

Desde el análisis del posicionamiento debemos tomar en consideración una distinción entre aquellos que se desempeñan en los organismos de la administración central del Estado - en otras palabras "de gobierno" - y aquellos que lo hacen a nivel local principalmente municipal-. En el caso de los primeros encontramos en general funcionarios con formación profesional, y que están en una gran proporción familiarizados con los principios de transparencia y el acceso a la información en la función pública. Entre los funcionarios del sector municipal, encontramos una gran presencia de personal administrativo, que no conoce a la transparencia como una cualidad deseable y modernizadora en la función pública, existiendo una heterogeneidad en las habilidades de aquellos funcionarios que cumplen el rol de hacerse cargo de las obligaciones de transparencia. Esta diferenciación plantea un desafío importante para la elaboración de propuestas de posicionamiento para el CPLT, tanto desde el lenguaje, la metodología y la profundi dad de los contenidos de promoción. Por esta razón, se puede identificar y realizar una propuesta analítica de posicionamiento 
y segmentación desde los siguientes roles:

1. Jefes de servicio: El posicionamiento en este nivel debiera abordar temáticas de cómo conocer en profundidad qué es la LT y cómo se produce un valor público en la función de su institución en esta temática, especialmente en los ámbitos de mejorar la gestión interna, la confianza en el liderazgo evitando la "discrecionalidad" y arbitrariedad, adquiriendo un sentido de seguridad respecto a la acciones y fundamentos divisionales del funcionamiento institucional.

2. Encargados de transparencia o enlaces de cada servicio: es relevante para el posicionamiento que en este nivel se cuente con conocimientos generales de la Ley y también específicos, por lo que resulta pertinente posicionarse con las exigencia normativas, con experiencias reales de organismos con buenas prácticas, segmentando las diversas necesidades y orientando la publicación de información de manera amigable para el ciudadano. Por otro lado, es relevante incentivar el desarrollo de una función especial para realizar la acción de gestionar las solicitudes de información, para que la canalización interna sea funcional, adecuada y oportuna.

3. Jefaturas y profesionales de áreas jurídicas: En este nivel el posicionamiento se vincula a un mayor nivel de conocimientos asociados a: análisis competencial del órgano requerido, causales de reserva y restricciones al principio de información, afectación de derechos de terceros y "aterrizaje" de la normativa a su propia realidad institucional.

4. Funcionarios a cargo de atención de público (Oficinas de Partes y OIRS): Deben conocer el ciclo completo que sigue un requerimiento de acceso a la información, como también en el valor público de la Transparencia y sus consecuencias - tanto para el servicio, como para ellos mismos en términos de su imagen pública-.

\section{PROPUESTAS PARA EL PO- SICIONAMIENTO DEL CPLT}

Se propone desarrollar una campaña comunicativa considerando los siguientes elementos:

1. Potenciar y fortalecer la imagen corporativa del CPLT, posicionándola como un organismo autónomo y garante del derecho de acceso a la información en Chile, con un rol de fiscalizador de los organismos de la administración del Estado y municipios.

2. El objetivo de la campaña masiva debe dirigirse con especial énfasis en los sectores socioeconómicos medios y bajos (C2, C3 y D) que por norma general tienen menor acceso a la información, y que según lo visto se beneficiarían mayormente con la obtención de información para resolver sus demandas sociales. La campaña debe focalizar en un manejo de los temas con pertinencia a las demandas.

3. La campaña debe desarrollar los contenidos en un lenguaje simple, cercano y amigable. Se debe incluir que el derecho al acceso a la información apalanca otros derechos ciudadanos, y que el CPLT garantiza este derecho de forma autónoma a los poderes de Estado.

4. Se sugiere que el diseño de campaña tenga un énfasis especial en los contextos territoriales concretos a los que va dirigido.

5. Resaltar como tema la idea de que para la ciudadanía acceder a la información pública "equilibra los poderes del Estado frente a la opinión y acción ciudadana" (Estudios Nacionales de Transparencia, 2013).

6. Respecto a los canales y medios de la campaña, se sugiere que sea una campaña con la radiodifusión como medio troncal y periférico. Es importante también que esta campaña se complemente con difusión en redes sociales y con el desarrollo y distribución de material impreso sobre capacitaciones nacionales y regionales.

Para las actividades de difusión y capacitación se proponen generar las siguientes acciones:

1. Estrategias basadas en la segmentación de clientes antes propuesta, focalizadas a audiencias determinadas de acuerdo a sus necesidades e intereses específicos.

2. Estrategias basadas en un programa de difusión que brinde elementos y herramientas a la sociedad civil a través de la promoción y comunicación del Derecho de Acceso a la Información.

a) En el caso de ciudadanos asociativos o dirigentes activos, elaborar estrategias de entrenamiento y capacitación basadas en actividades que detecten necesidades sociales específicas y puedan traducirlas a los procedimientos de solicitud de información y de búsqueda de antecedentes 
mediante Transparencia Activa, a través de metodologías de taller especificas al contexto de la audiencia y en relación a las necesidades que los participantes identifiquen.

b) Fomentar el trabajo con profesionales que trabajan en el ámbito social y que puedan amplificar los temas asociados a la LT y el rol CPLT, realizando capacitación a potenciales capacitadores.

c) Desarrollo de material o manuales ciudadanos que permitan apoyar las actividades antes señaladas, pudiendo penetrar "mano a mano" a muchas otros ciudadanos y generar un mayor posicionamiento.

d) Reforzar la la plataforma online www.educatransparencia.cl, la que permite el libre uso y utilización de distintas herramientas educacionales, entre las que destacan una serie cápsulas educativas que tratarán temáticas generales sobre el derecho acceso a la información, la Ley de Transparencia y el Consejo. Además, contempla la impartición de cursos virtuales (e-learning), cada uno de ellos constituido por una serie de componentes teóricos y prácticos en distintos niveles, a los cuales se podrá acceder sin costo alguno y en la propuesta temática que los usuarios seleccionen.

3. En el caso de los clientes públicos, fortalecer actividades de marco de capacitación global en diversos aspectos de la LT, dirigida a servicios públicos y municipales. $\mathrm{Su}$ foco apunta a dar a conocer de modo amplio aquellos aspectos relevantes de la LT, presentando el rol que cumple el CPLT a través de sus funciones. Los canales a utilizar pueden ser cursos a través de un portal educativo a distancia, como también relatorías presenciales informativas en organismos y la gestión de videoconferencias en casos particulares.

a) Los funcionarios pueden ser desde jefes de servicio, enlaces, funcionarios OIRS y otros funcionarios públicos, focalizando los contenidos en el funcionamiento del CPLT, la transparencia activa, el ámbito normativo del CPLT, y en especial los procedimientos administrativos y la gestión de solicitudes de información al interior de los organismos.

b) Construir actividades de formación específica y experta, especialmente para solventar necesidades más particulares en aquellos funcionarios públicos y municipales que trabajan directamente en temáticas de transparencia en sus respectivos servicios, con un foco particular en la aplicabilidad de los procedimientos dentro del contexto particular de quien requiere de la capacitación, es decir focalizada a la realidad institucional concreta. En este caso los clientes son los jefes del área jurídica y encargados de transparencia de los organismos. Los contenidos de abordaje debieran ser la principal jurisprudencia de CPLT (en decisiones relativas a servicio público específico a capacitar), revisión de informes de fiscalización en TA y DAI, análisis de la temática de protección de datos personales, las herramientas que CPLT pone a disposición de los servicios, y también los eventuales procedimientos sancionatorios que puede entablar el CPLT.

c) Realizar actividades de capacitación a funcionarios Municipales, tanto en procesos de fiscalización de TA y Derecho de Acceso a la Información, centrados en dar a conocer el modelo de cumplimiento en transparencia activa a nivel municipal y dar a conocer y capacitar a funcionarios públicos y municipales en la nueva Instrucción General de Derecho de Acceso a la Información. Los canales propuestos son actividades presenciales de manera macro zonal a nivel regional o provincial, y también la promoción de cursos a distancia con cursos especialmente enfocados a este grupo. Los tipos de clientes objetivos son los administradores municipales, los profesionales jurídicos, los encargados de Transparencia municipal, $\mathrm{y}$ otros funcionarios municipales ligados a los requerimientos de la LT, como los Diádicos, Direcciones de Obras, Direcciones de Tránsito, etc.

\section{CONCLUSIONES}

Existe una necesidad importante de desarrollar una línea de acción tendiente a posicionar el DAI en la ciudadanía y la sociedad civil, como también en los funcionarios públicos .

Es relevante desarrollar una estrategia que expanda el derecho a la información y posicione al CPLT a través de la identificación de distintos segmentos o públicos objetivos. Por tanto, como principio general, las propuestas estratégicas se han orientado a un abordaje pragmático que potencie actividades de difusión, y especialmente de segmen- 
tación de los diversos "clientes objetivos", públicos y privados. Las acciones del CPLT se deben enfocar a identificar focos o sectores de carácter crítico para la ciudadanía, en términos de acceso a información pública y transparencia, como los de "Vivienda", "Salud" y "Educación". Así podemos pensar la Transparencia como un vehículo, para arribar a otros derechos de primera prioridad.

En conjunto con ello se requiere incorporar una óptica ciudadana en el centro de la discusión de las actividades y orientar las acciones hacia las necesidades de los usuarios, relevando la pertinencia y utilidad social de la información pública. De es- ta manera se favorece la promoción, construcción e institucionalización de una cultura de la transparencia en Chile, garantizando el derecho de acceso a la información de las personas.

\section{Referencias}

Biblioteca del Congreso Nacional (2013). Ley de Transparencia 20.285. Santiago de Chile.

Estudios Nacionales de Transparencia (2013). Consejo para la transparencia. 